\title{
Knockout of cytochrome P450 3A yields new mouse models for understanding xenobiotic metabolism
}

\author{
Antonius E. van Herwaarden, ${ }^{1}$ Els Wagenaar, ${ }^{1}$ \\ Cornelia M.M. van der Kruijssen, ${ }^{1}$ Robert A.B. van Waterschoot, ${ }^{1}$ \\ Johan W. Smit, ${ }^{2}$ Ji-Ying Song, ${ }^{3}$ Martin A. van der Valk, ${ }^{3}$ Olaf van Tellingen, ${ }^{4}$ \\ José W.A. van der Hoorn, ${ }^{5}$ Hilde Rosing, ${ }^{6}$ Jos H. Beijnen, ${ }^{6}$ and Alfred H. Schinkel ${ }^{1}$
}

\begin{abstract}
${ }^{1}$ Division of Experimental Therapy, The Netherlands Cancer Institute, Amsterdam, The Netherlands. ${ }^{2}$ Department of Clinical Pharmacology, Johnson \& Johnson Pharmaceutical Research and Development LLC, Beerse, Belgium. ${ }^{3}$ Department of Experimental Animal Pathology and ${ }^{4}$ Department of Clinical Chemistry, The Netherlands Cancer Institute, Amsterdam, The Netherlands. ${ }^{5}$ TNO BioSciences and Department of Cardiology, Leiden University Medical Center, Leiden, The Netherlands. ${ }^{6}$ Department of Pharmacy and Pharmacology, Slotervaart Hospital, Amsterdam, The Netherlands.
\end{abstract}

\begin{abstract}
Cytochrome P450 3A (CYP3A) enzymes constitute an important detoxification system that contributes to primary metabolism of more than half of all prescribed medications. To investigate the physiological and pharmacological roles of CYP3A, we generated Cyp3a-knockout $\left(\mathrm{Cyp}^{3} \mathrm{a}^{-/-}\right)$mice lacking all functional Cyp3a genes. $\mathrm{Cyp}^{3} \mathrm{a}^{-/-}$mice were viable, fertile, and without marked physiological abnormalities. However, these mice exhibited severely impaired detoxification capacity when exposed to the chemotherapeutic agent docetaxel, displaying higher exposure levels in response to both oral and intravenous administration. These mice also demonstrated increased sensitivity to docetaxel toxicity, suggesting a primary role for Cyp3a in xenobiotic detoxification. To determine the relative importance of intestinal versus hepatic Cyp3a in first-pass metabolism, we generated transgenic $\mathrm{Cyp} 3 \mathrm{a}^{-/-}$mice expressing human CYP3A4 in either the intestine or the liver. Expression of CYP3A4 in the intestine dramatically decreased absorption of docetaxel into the bloodstream, while hepatic expression aided systemic docetaxel clearance. These results suggest that CYP3A expression determines impairment of drug absorption and efficient systemic clearance in a tissue-specific manner. The genetic models used in this study provide powerful tools to further study CYP3A-mediated xenobiotic metabolism, as well as interactions between CYP3A and other detoxification systems.
\end{abstract}

\section{Introduction}

Cytochrome P450 3A (CYP3A) enzymes are heme-containing monooxygenases responsible for the oxidative metabolism of many endogenous and xenobiotic compounds. They are the most abundant CYPs in human liver and small intestine and involved in the primary metabolism of, among others, toxins, carcinogens, bile acids, steroid hormones, and more than $50 \%$ of the drugs used in the clinic today (1). The extremely wide substrate specificity of CYP3As, including many endogenous compounds, has led to numerous hypothesized physiological functions of CYP3A (1-5). In humans, CYP3A4 is generally the most abundant hepatic and intestinal form, accounting on average for $95 \%$ of the combined liver CYP3A mRNA pool in white individuals (6). CYP3A expression can vary as much as 40 -fold in liver and small intestine donor tissues (7). These large inter- and intraindividual differences can result from variable control of gene expression by endogenous molecules such as circulating hormones, or by drugs and food-derived xenobiotics, and from genetic polymorphisms (7). Additionally, food constituents (e.g., grapefruit juice) or

Nonstandard abbreviations used: AUC, area under the curve; Сyp3a, cytochrome P450 3A; Сyp3a-/-A mice, Сyp3a-knockout mice with apoE promoter-driven liver-

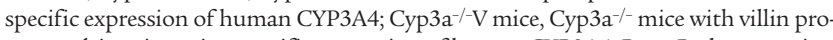
moter-driven intestine-specific expression of human CYP3A4; P-gp, P-glycoprotein.

Conflict of interest: J.W. Smit receives income from Johnson \& Johnson Pharmaceutical Research and Development LLC. The authors have declared that no conflict of interest exists.

Citation for this article: J. Clin. Invest. 117:3583-3592 (2007). doi:10.1172/JCI33435. drugs (e.g., the HIV protease inhibitor ritonavir) can profoundly inhibit CYP3A (8). Consequently, the oral availability and systemic clearance of CYP3A substrate drugs can vary extensively among patients, with sometimes dramatic consequences for drug efficacy and toxicity. This makes CYP3A one of the most important factors in variable drug exposure.

As one interesting example, the anticancer drug docetaxel (Taxotere) has a large interpatient variability in exposure and drug clearance. Like most cytotoxic anticancer drugs, docetaxel has only a narrow therapeutic window, and variable docetaxel exposure can result in severe toxicity or, alternatively, subtherapeutic levels (9). Four main docetaxel metabolites (M-1, $\mathrm{M}-2, \mathrm{M}-3$, and $\mathrm{M}-4$ ) have been identified in human feces. The primary metabolite, $\mathrm{M}-2$, is formed by CYP3A through oxidation of the tert-butyl ester side group; further oxidations lead to the 3 others. All these metabolites are far less active than the parent docetaxel $(9,10)$. Therefore, CYP3A might very well be important in variable docetaxel exposure and related inefficacy or toxicity risks $(10-12)$.

Although many in vitro assays are available that indicate whether a drug is broken down by CYP3A, this does not always properly reflect the extent to which a drug is affected in an intact organism. In vivo factors such as blood flow, rate and extent of cell and tissue distribution, and interactions with other drug-handling systems such as drug transporters can markedly complicate matters. It is thus important to be able to systematically assess the in vivo impact of CYP3As on drug metabolism in order to minimize 
$\mathbf{A}$
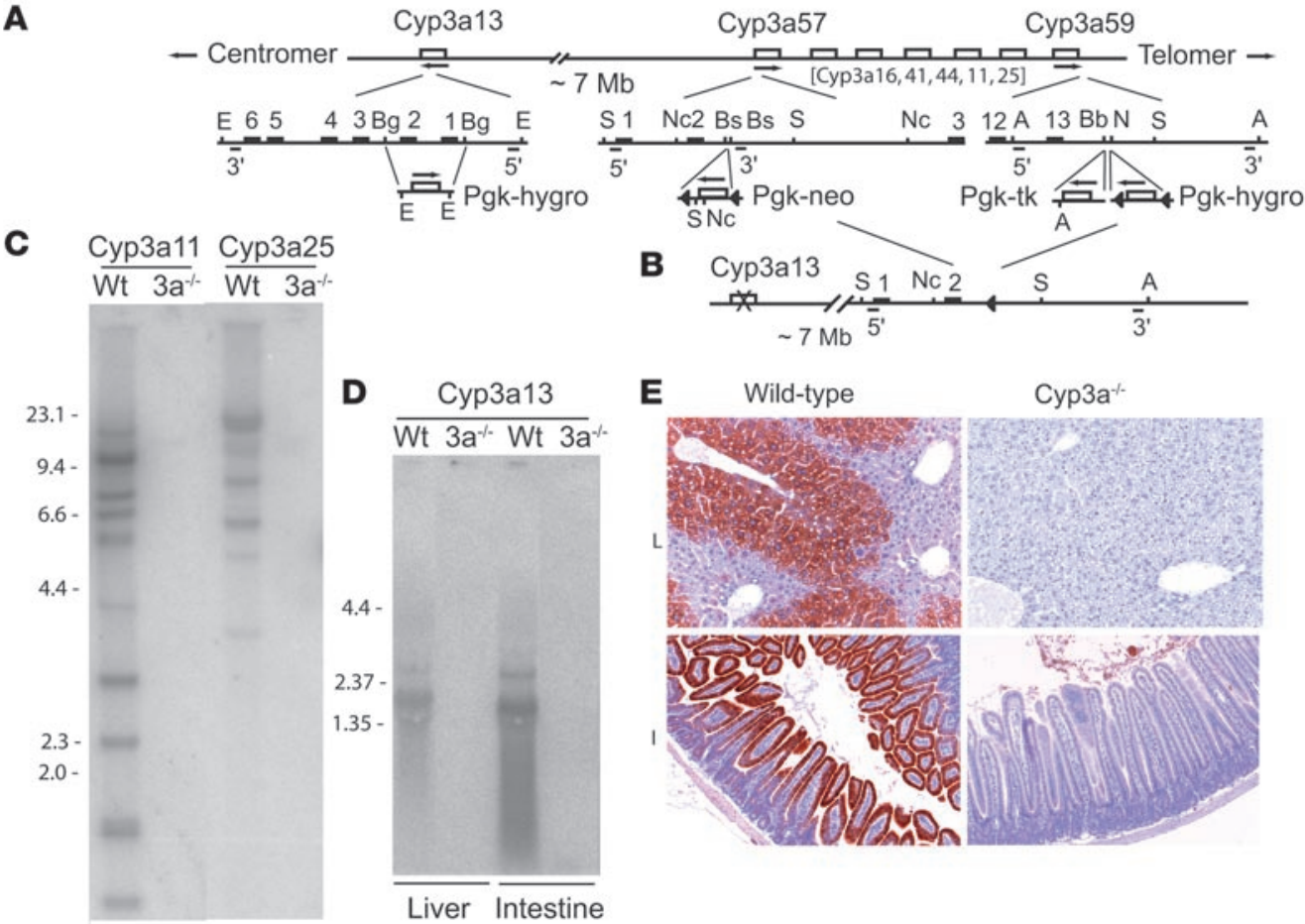

Figure 1

Generation of Cyp3a-/- mice. (A) For disruption of Сyp3a13, a 4-kb domain including exons 1 and 2 and the putative promoter region was replaced with an inverted Pgk-hygromycin cassette. Between exons 2 and 3 of Cyp3a57 an inverted Pgk-neomycin cassette with loxP sequences was inserted and an inverted $P g k$-thymidine kinase and an inverted Pgk-hygromycin cassette with loxP sequences was inserted $2.2 \mathrm{~kb}$ downstream of exon 13 of Сур3а59. The Сур3a genes within the cluster were excised from the genome by Pgk-Cre recombinase transfection. Cyp3a pseudogenes are not shown. (B) Structure of the region after deletion of the Cyp3a cluster and Cyp3a13 disruption. For Southern blot analysis, $5^{\prime}$ and $3^{\prime}$ probes were used on digested genomic DNA. Triangles indicate lox $P$ sequences, numbered boxes indicate exons, arrows indicate transcriptional orientation. E, EcoRV; Bg, Bglll; S, Scal; Nc, Ncol; Bs, BstEll; A, Asp718; Bb, Bbrp1; N, Nhel. (C) Southern blot analysis of kidney DNA digested with Asp718 from Cyp3a ${ }^{-/}\left(3 \mathrm{a}^{-/}\right)$mice and probed with Cyp3a11 or Cyp3a25 cDNA, demonstrating the absence of all Cyp3a cluster genes. (D) Northern blot analysis for liver and intestinal RNA probed with Cyp3a13 cDNA, demonstrating the absence of Сyp3a13 RNA in Cyp3a ${ }^{-/-}$mice. (E) Immunohistochemical detection of Cyp3a in liver (L) and small intestine (I) of wild-type but not Cyp3a ${ }^{-/-}$mice.

possible toxicity or inefficacy of drugs. As CYP3A is localized in both liver and intestine, it can make a major contribution to presystemic elimination of substrate drugs following oral administration (first-pass metabolism). However, assessments of the relative importance of intestinal versus hepatic contribution of CYP3Amediated first-pass metabolism are difficult to make and subject to extensive discussion (13-15).

To systematically assess the in vivo impact of CYP3As on physiology and pharmacology, and the relative contributions of the intestine and liver to first-pass metabolism, we have generated and characterized Cyp3a-knockout mice and transgenic mice with human CYP3A4 expression in liver or intestine in a Cyp3a-knockout background. Based on amino acid identity $(62.6 \%-75.3 \%)$, there are no clear orthologous pairs between the 4 human CYP3As (CYP3A4, -5, -7, and -43) and the 8 fulllength mouse Cyp3as. Moreover, tissue distribution and substrate specificities of these proteins show very extensive overlap. It is therefore probable that the combined functions of all the mouse Cyp3as correspond to the combined functions of all the human CYP3As. For this reason we decided that the ablation or inactivation of all full-length murine Cyp $3 a$ genes would likely be essential to obtain a useful Cyp3a-knockout model.

\section{Results}

Generation of Cyp3a-knockout mice. In the mouse, 8 full-length Сyp $3 a$ genes and 3 pseudogenes have been identified (16). The Cyp3a11, -3a16, -3a25, -3a41, -3a44, -3a57, -3a58-ps, -3a59, and $-3 a 60-p s$ genes are clustered within a genomic region of approximately $0.8 \mathrm{Mb}$, whereas Cyp3a13 and Cyp3a61-ps are located approximately $7 \mathrm{Mb}$ centromeric to the cluster. The Cyp3a13 gene was disrupted in ES cells by replacing the putative promoter region and exons 1 and 2 with a Pgk-hygromycin cassette. All clustered Cyp3a genes were deleted by inserting loxP sites in the Cyp3a57 gene and downstream of the Cyp3a59 gene of ES cells followed by Pgk-Cre recombinase transfection (Figure 1, A and B). Blastocyst injection of ES cell clones yielded Cyp3a clusterknockout and Cyp3a13-knockout mice, which could be crossed to obtain complete Cyp3a family-knockout (Cyp3a-/-) mice, as the approximately $7-\mathrm{Mb}$ distance between the knockout alleles allowed a sufficiently high crossover frequency.

Deletion of the Cyp3a cluster genes and absence of Cyp3a13 RNA in Cyp3a-/- mice was verified by Southern and Northern blot analysis, respectively. DNA of wild-type and Cyp3a $\mathrm{a}^{-/-}$mice was probed with Cyp3a11 or Cyp3a25 cDNAs, which cross-hybridize with Cyp3a16, $-3 a 41$, and $-3 a 44$ or with Cyp3a57 and Cyp3a59, 




$\mathbf{B}$

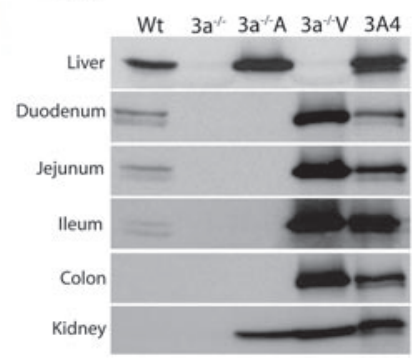

\section{Figure 2}

CYP3A4 expression in transgenic mice. (A) Schematic structure of villin promoter-driven expression cassette, containing human CYP3A4 cDNA. (B) Western blot analysis of crude membrane fractions of liver and intestine of wild-type and Cyp3 $\mathrm{a}^{-/-}$mice and transgenic mice with human CYP3A4 expression in liver $\left(3 \mathrm{a}^{-/-} \mathrm{A}\right)$ or intestine $\left(3 \mathrm{a}^{-/-} \mathrm{V}\right)$, in a Cyp3a $\mathrm{a}^{-1-}$ background. Blots were probed with an antibody raised against human CYP3A4. Cyp3a expression was found in wild-type but not in Cyp3a $\mathrm{a}^{-/}$tissues. Expression of human CYP3A4 was seen in liver and kidney, but not intestine, of transgenic Cyp3a--A mice. Expression of human CYP3A4 was seen in intestine and kidney, but not liver, of transgenic Сyp3 $\mathrm{a}^{-1-} \mathrm{V}$ mice. 3A4, CYP3A4 standard (0.05 pmol). $20 \mu \mathrm{g}$ of liver or intestinal protein was loaded, except in the case of the

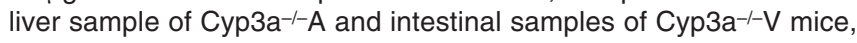
which had $2 \mu \mathrm{g}$ loaded. $30 \mu \mathrm{g}$ of kidney protein was loaded.

respectively. The extensive hybridization present in wild-type mice was absent in Cyp3a-/- mice (Figure 1C). Cyp3a13 RNA was present in wild-type liver and intestine but completely absent in Cyp3a-/tissues (Figure 1D). A $32 \mathrm{~K}$ mouse oligoarray analysis revealed that RNA levels of all Cyp3a genes on the array (Cyp3a11, -3a13, -3a16, $-3 a 25$, and -3a41) were sharply "downregulated" in liver and intestine of adult male Cyp3a-/- mice.

We performed immunohistochemistry with an anti-rat Cyp3a1 polyclonal antibody that cross-recognizes murine Cyp3a. Liver of wild-type mice displayed strong immunoreactivity in a zonated distribution pattern, present at the perivenous (downstream) region, as described previously (17). This immunoreactivity was completely absent in Cyp3a $\mathrm{a}^{-/-}$mice (Figure 1E). Similarly, no immunoreactivity was observed in Сyp3 $\mathrm{a}^{-/-}$intestine, whereas wild-type mice displayed strong immunoreactivity at the intestinal villus tips (Figure 1E). These results confirm the loss of Cyp3a protein in Cyp3a-/- mice.

Cyp3 $3 a^{-1-}$ mice are viable and fertile and do not display obvious physiological abnormalities. We anticipated that the deletion and disruption of an entire family of xenobiotic-, steroidand bile acid-metabolizing enzymes could have marked physiological consequences. Interestingly, however, Cyp3a $\mathrm{a}^{-/-}$mice were viable and fertile. Hematological, plasma clinical chemistry and pathological examination of male and female Cyp3a-/- mice $(n=5)$ at approximately 12 weeks of age $\mathrm{did}$ not reveal any marked abnormalities, nor did pathological examination between 67 and 84 weeks of age ( $n=4$, both sexes) (data not shown). As Cyp3a metabolizes many steroid hormones, endogenous plasma estradiol and testosterone levels were determined, but these were not different in wild-type and Сyp3a-/- mice (estradiol in plasma of diestrous wild-type vs. Cyp3a- females: $59 \pm 10$ vs. $50 \pm 9$ pM; $P=0.20$; testosterone in plasma of wild-type vs. Cyp3a- $\mathrm{a}^{-1-}$ males: $38 \pm 9$ vs. $40 \pm 2 \mathrm{nM}$; $P=0.72)$. Moreover, because several clinical studies have associated hypertension with polymorphisms in CYP3A genes $(3,4)$, we measured systolic (SBP), diastolic (DBP), and mean blood pressure $(\mathrm{MBP})$ and average heart rate of wild-type and Cyp3a- $\mathrm{a}^{-/}$mice. No differences were observed (SBP $116 \pm 24$ vs. $110 \pm 13, P=0.61$; DBP $91 \pm 21$ vs. $84 \pm 7, P=0.44$; MBP $99 \pm 22$ vs. $93 \pm 9, P=0.50$; heart rate $633 \pm 30$ vs. $653 \pm 81, P=0.58)$.

A $32 \mathrm{~K}$ mouse oligoarray analysis was used to compare RNA from liver, small intestine, and kidney of wild-type and Cyp3a-/- adult males. In the liver, a modest number of significantly $\left[{ }^{2} \log (\right.$ ratio $)>1$ or $<-1 ; P<0.01]$ upregulated $(n=35)$ and downregulated $(n=10)$ annotated genes was observed, in addition to the "downregulated" Cyp3a genes. In the small intestine, there were 13 upregulated genes and 25 downregulated (in addition to the Cyp3as), and for kidney this was 27 and 23, respectively. Interestingly, most genes involved in metabolism or drug disposition, including NADPHcytochrome reductase, Pxr, Car, various Cyps and multidrug transporters (P-glycoprotein [P-gp], Bcrp1, Mrps) were not markedly differently expressed in Cyp3a- mice, although mildly upregulated Сур2b9, Сур2b10, Slco1a4, and Mrp3 were observed in liver and upregulated Cyp2c55 in liver and intestine (data deposited at ArrayExpress; EBI). Overall, no pronounced changes in gene regulation were observed. Taken together, the results indicate that the ablation of all Cyp3a genes does not appear to cause marked physiological abnormalities in the Cyp3 $\mathrm{a}^{-/-}$mice, at least not under the sheltered conditions of our animal facility.

Humanized mice with stable transgenic CYP3A4 expression in liver or intestine of Cyp3a knockouts. CYP3A4-transgenic mice were generated using a villin promoter-driven expression cassette, containing human CYP3A4 cDNA (see Supplemental Data [available online with this article; doi:10.1172/JCI33435DS1] and Figure 2A), aiming primarily for protein expression in the intestine. Homozygous villin-CYP3A4-transgenic mice were viable and fertile. Lifespan, body weight, hematological, and clinical chemistry analysis of plasma and pathological analysis did not reveal obvious abnormalities, although the mucosa of the small intestine showed changes of increased cellularity mainly at the villi and mildly hypertrophic epithelium (data not shown). CYP3A4-
Table 1

Kinetic parameters for docetaxel metabolite M-2 formation by liver and intestinal microsomes

\begin{tabular}{|c|c|c|c|c|c|c|}
\hline \multirow[b]{2}{*}{ Strain } & \multicolumn{3}{|c|}{ Liver } & \multicolumn{3}{|c|}{ Intestine } \\
\hline & $K_{\mathrm{m}}{ }^{A}$ & $V_{\max }^{B}$ & $\mathrm{Cl}_{\mathrm{int}} \mathrm{C}$ & $K_{\mathrm{m}}{ }^{A}$ & $V_{\max }^{B}$ & $\mathrm{Cl}_{\mathrm{int}} \mathrm{C}$ \\
\hline WT & $2.0 \pm 0.3$ & $235 \pm 5$ & 118 & $0.6 \pm 0.1$ & $14 \pm 0.9$ & 24 \\
\hline Cyp3a-/- & $-D$ & $-D$ & $-\mathrm{D}$ & $-D$ & $-D$ & $-D$ \\
\hline Сyp3a-1-A & $2.2 \pm 0.2$ & $173 \pm 5$ & 79 & $-D$ & $-D$ & $-D$ \\
\hline Сур3a--V & $-D$ & $-D$ & $-D$ & $0.4 \pm 0.1$ & $25 \pm 2.8$ & 59 \\
\hline Human & $1.3 \pm 0.2$ & $81 \pm 6$ & 62 & $1.3 \pm 0.0$ & $53 \pm 1.6$ & 40 \\
\hline
\end{tabular}

Incubations were performed as described in Methods. All values are the mean \pm SD of 3 independent experiments, except for human intestinal microsomes, which were determined in duplicate. ${ }^{A} K_{\mathrm{m}}$ expressed in $\mu \mathrm{M}$. ${ }^{\mathrm{B}} V_{\max }$ expressed in $\mathrm{pmol} / \mathrm{min} / \mathrm{mg}$ protein. ${ }^{C} \mathrm{Cl}$ int expressed in $\mu \mathrm{l} / \mathrm{min} / \mathrm{mg}$ protein. ${ }^{\mathrm{N} N o}$ metabolite detected. 

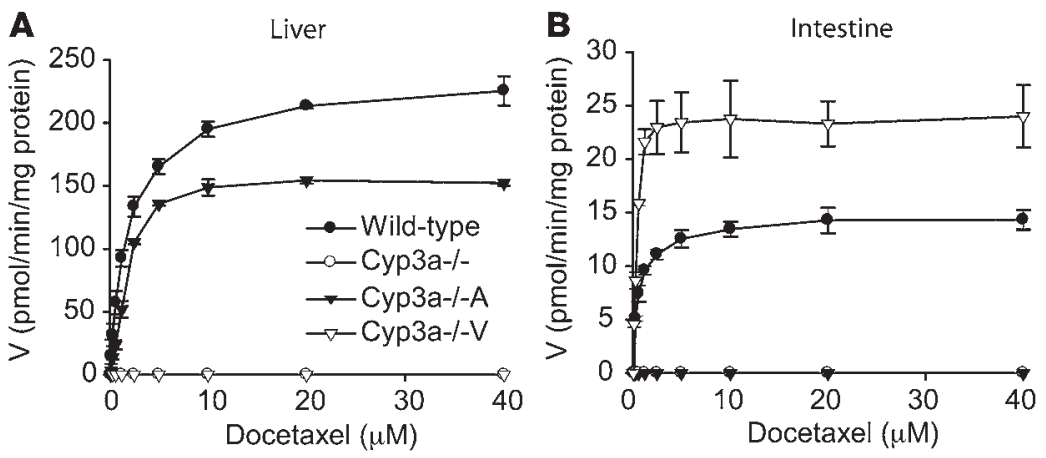

Figure 3

Metabolism of docetaxel in microsomal fractions derived from liver (A) or intestine (B) be detected in liver- or intestine-derived microsomal fractions of Cyp3a $\mathrm{a}^{-/-}$mice, nor in liver or intestinal microsomal fractions of $\mathrm{Cyp} \mathrm{a}^{-/-} \mathrm{V}$ and $\mathrm{Cyp} 3 \mathrm{a}^{--} \mathrm{A}$, respectively. of wild-type, Сyp3a $\mathrm{a}^{--}$, Сyp3 $\mathrm{a}^{-/} \mathrm{A}$, and Cyp3a $\mathrm{a}^{-/} \mathrm{V}$ mice. No metabolite formation could

microsomes (Figure 3 and Table 1). In accordance with the expression profile of human CYP3A4 in the transgenic mice, M-2 formation was detected in hepatic but not intestinal microsomes from Сур3 $\mathrm{a}^{-/-}$A mice, whereas M-2 formation was found in Cyp3a-/-V intestinal but not hepatic microsomes. $K_{\mathrm{m}}$ values for liver microsomes were similar in wildtype and Сyp3a-/-A mice, whereas the maximum turnover $\left(V_{\max }\right)$ in the Cyp3a-/-A strain was $74 \%$ of that in wild type. Also for the intestinal microsomes comparable $K_{\mathrm{m}}$ values were measured, but a roughly 2-fold higher $V_{\max }$ was found in the Cyp3a-/-V strain when compared with wild-type. These results establish the absence of docetaxel M-2 metabolite formation in liver and intestine of Cyp3a-/- mice, whereas activity in transgenic microsomes (compare intrinsic clearance $\left.\left[\mathrm{Cl}_{\text {int }}\right]\right)$ was of the same order as endogenous murine Cyp3a and CYP3A in human pooled microsomes (Table 1).

transgenic mice with apoE promoter-driven liver expression were described previously (18). Both transgenic strains were crossed into a Cyp3a-/- background and bred to homozygosity of the transgenes. We hereafter refer to these strains as Cyp3a-/-V

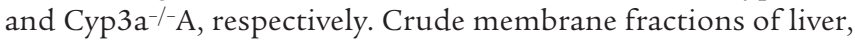
duodenum, jejunum, ileum, colon, and kidney of wild-type, Cyp3a-/-, Cyp3a-/-A, and Cyp3a-/-V mice were analyzed for expression of CYP3A4 by Western blotting using a rabbit anti-human CYP3A4 polyclonal antibody, which, at presumably lower affinity, also cross-recognizes murine Cyp3a. As intended, CYP3A4 in Сур $3 \mathrm{a}^{-/-V}$ mice was expressed in high amounts in the duodenum, jejunum, ileum, and colon but not in liver (Figure 2B). CYP3A4 in Cyp3a-/-A mice was expressed in the liver but not in the intestine (18). CYP3A4 in Cyp3a $\mathrm{a}^{-/-} \mathrm{A}$ and Cyp3a $\mathrm{a}^{-/-} \mathrm{V}$ mice was also expressed at low levels in kidney (note that $30 \mu \mathrm{g}$ kidney protein was loaded, instead of $2 \mu \mathrm{g}$ for the Cyp3 $3 \mathrm{a}^{-/-} \mathrm{A}$ liver and Cyp3a-/-V intestinal samples) (Figure 2B). The contribution of this renal CYP3A4 to overall drug metabolism is probably modest, also considering that liver or intestine constitute a much larger fraction of the total body weight. The seemingly high expression level of transgenic CYP3A4 in liver and intestine of Cyp3a-/-A and Cyp3a--V mice compared with Cyp3a in wild-type mice is probably explained by a lower affinity of the anti-human CYP3A4 antibody for murine Cyp3a versus human CYP3A4 (see also below and Table 1).

Absent docetaxel M-2 metabolite formation in Cyp3a-/microsomes is reinstated to wild-type levels in transgenic Cyp3 $3 a^{-/} A$ and Cyp3 $3 a^{-/-} V$ microsomes. We wanted to assess whether the absence of Сyp3a in Сyp3a-/mice resulted in functionally impaired metabolic capacity, as well as how the transgenic CYP3A4 in Сур $3 \mathrm{a}^{-/-} \mathrm{A}$ and Сyp3a-/-V mice would functionally compare with endogenous murine Cyp3a activity and with CYP3A activity in human tissues. We therefore measured metabolism of the anticancer drug docetaxel to its primary M-2 metabolite in microsomes from liver and intestine of wild-type, Сyp3a--, Cyp3a-/-A, and Cyp3a-/-V mice and in pooled human samples. M-2 was efficiently formed by all wild-type microsomes, obeying Michaelis-Menten kinetics, but was undetectable with Сур3a-/-

\section{Table 2}

Pharmacokinetic parameters estimated for docetaxel $(10 \mathrm{mg} / \mathrm{kg})$ in wild-type, Cyp3a--, Cyp3a ${ }^{-/-} \mathrm{A}$, and Cyp3a ${ }^{-/-} \mathrm{V}$ mice

\begin{tabular}{lcccr} 
& WT & \multicolumn{1}{c}{ Cyp3a- } & \multicolumn{1}{c}{ Cyp3a-/-A } & Cyp3a--V \\
$\mathrm{AUC}_{\text {iv }}(\mathrm{ng} \bullet \mathrm{h} / \mathrm{ml})$ & $777.1 \pm 22^{\mathrm{A}}$ & $5,256 \pm 224$ & $976.9 \pm 32^{\mathrm{A}}$ & $3,777 \pm 89^{\mathrm{B}}$ \\
$\mathrm{AUC}_{0}(\mathrm{ng} \cdot \mathrm{h} / \mathrm{ml})$ & $63.0 \pm 4.4^{\mathrm{B}}$ & $1,115 \pm 115$ & $503.7 \pm 38^{\mathrm{C}}$ & $67.0 \pm 7.3^{\mathrm{B}}$ \\
$\mathrm{Cl}(\mathrm{ml} / \mathrm{h} / \mathrm{kg})$ & $12,868 \pm 372^{\mathrm{A}}$ & $1,903 \pm 81$ & $10,237 \pm 335^{\mathrm{A}}$ & $2,647 \pm 62^{\mathrm{B}}$ \\
$\mathrm{F}(\%)$ & $8.1 \pm 0.6^{\mathrm{C}}$ & $21 \pm 2.4$ & $52 \pm 4.3^{\mathrm{B}}$ & $1.8 \pm 0.2^{\mathrm{B}}$ \\
$\mathrm{C}_{\max }(\mathrm{ng} / \mathrm{ml})$ & $44.2 \pm 7.5^{\mathrm{B}}$ & $638 \pm 127$ & $422 \pm 42$ & $44.9 \pm 4.9^{\mathrm{B}}$ \\
\hline
\end{tabular}

Area under the plasma concentration versus time curve (AUC), clearance (Cl), oral bioavailability $(\mathrm{F})$, and maximal concentration obtained after oral administration $\left(\mathrm{C}_{\max }\right)$ are indicated. Values represent the mean $\pm \mathrm{SE}(n=4)$. ${ }^{\mathrm{A} P}<0.001,{ }^{\mathrm{B}} P<0.01,{ }^{\mathrm{C}} P<0.05 \mathrm{com}$ pared with Сyp3a ${ }^{-/-}$mice. 

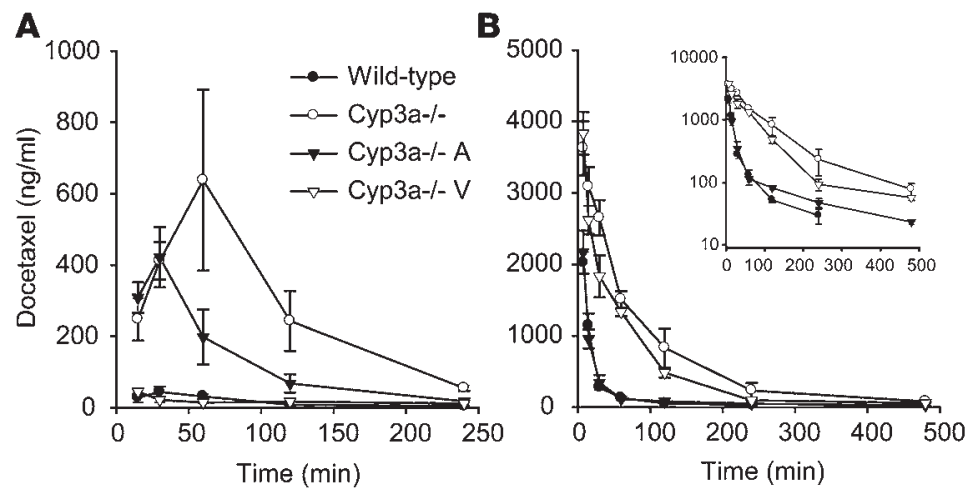

Figure 4

Cyp3a limits docetaxel exposure. Expression of CYP3A4 in intestine virtually blocks docetaxel entry upon oral administration, whereas liver CYP3A4 expression predominantly limits systemic exposure. Plasma concentration versus time curve of docetaxel after oral (A) or i.v. (B) docetaxel administration $(10 \mathrm{mg} / \mathrm{kg}$ )

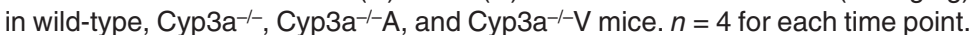
Note differences in time and concentration scales between $\mathbf{A}$ and $\mathbf{B}$. Differences between wild-type and Cyp3a ${ }^{-1-}(P<0.01)$ and Cyp3a ${ }^{-1-} \mathrm{A}$ and $C y p 3 \mathrm{a}^{-/-} \mathrm{V}$ $(P<0.05)$ were significant for all time points after i.v. and oral administration. Inset in B shows the semi-log plot of the data.

plasma AUC in Cyp3 $3 \mathrm{a}^{-/-V}$ mice was only $28 \%$ lower than that in Cyp3a-- mice. In contrast, the expression of CYP3A4 in liver alone $\left(\right.$ Cyp $3 \mathrm{a}^{-/-\mathrm{A}}$ ) reduced plasma docetaxel AUC more than 5-fold, to levels close to those in wild-type mice. This illustrates the predominant impact of hepatic metabolism on clearance after i.v. administration. Interestingly, when human CYP3A4 was present in the intestine alone $\left(\right.$ Сур $\left.3 \mathrm{a}^{-/-} \mathrm{V}\right)$, this dramatically reduced docetaxel plasma exposure after oral administration to levels comparable to those in wild-type mice (16.6-fold; Figure 4A and Table 2). In contrast, the substantial liver expression of CYP3A4 (Сур3 $\mathrm{a}^{-/-}$A) had just a 2.2-fold reducing effect on the oral AUC. The pronounced difference in impact between hepatic and intestinal CYP3A4 on systemic clearance versus oral uptake of docetaxel is illustrated by the apparent oral bioavailability $(F)$. This was $52 \%$

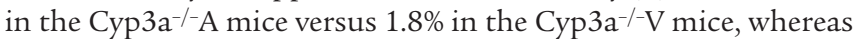
in $\mathrm{Cyp}^{3} \mathrm{a}^{-/-}$mice it was $21.2 \%$ (Table 2).

The reduction of docetaxel exposure by endogenous Cyp3a in wild-type mice and by transgenic CYP3A4 in the intestine of Cур $3 \mathrm{a}^{-/-V}$ mice could be inhibited by oral administration of the CYP3A inhibitor ritonavir $(50 \mathrm{mg} / \mathrm{kg})$, further supporting the primary role of Cyp3a and CYP3A4 in these changes. Inhibition of Cyp3a/CYP3A4 by ritonavir increased plasma docetaxel levels to near those observed in Cyp3a-- mice (Figure 5A). Moreover, no differences between plasma docetaxel levels in Cyp3 $\mathrm{a}^{-/-}$mice treated with or without ritonavir were observed. This indicates that ritonavir could nearly completely inhibit (primarily intestinal) Cyp3a or CYP3A4 and that ritonavir had very few other effects on docetaxel disposition.

Together, these data illustrate the predominant effect of intestinal CYP3A4 on the first-pass metabolism of docetaxel. Clearly, intestinal CYP3A4 can operate, independently of the liver, as a highly efficient barrier to the penetration of this drug from the intestinal lumen.

Docetaxel and metabolite tissue distribution and excretion in the absence of Сур 3 a. To investigate the role of Сyp3a and of liver- and intestine-specific CYP3A4 expression in the distribution, tissue exposure, and metabolic fate of docetaxel, we isolated several organs

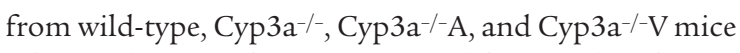
1 hour after i.v. administration of docetaxel and measured docetaxel and M-1, M-2, M-3, and M-4 metabolites by HPLC. As M-1, M-3, and M-4 are all derived from the initial M-2 metabolite, we pooled the results for all (M1-4) to assess the quantity of M-2 initially formed. Wild-type lung, kidney, and spleen do not have abundant Cyp3a expression, and despite the diverse plasma docetaxel levels between the strains at 1 hour, these tissues did not display large changes in docetaxel accumulation (Table 3 ). In contrast, liver and intestinal tissue, organs in which Cyp3a/CYP3A is abundant in wildtype or transgenic mice, showed marked differences in docetaxel and metabolite accumulation. Cyp3a- $\mathrm{a}^{-/-}$mice had a greater than 7-fold higher docetaxel level in the liver and a 5-fold higher level in small intestine than wildtype controls. Metabolite formation in liver was reduced 24-fold in Сyp3a- $\mathrm{a}^{-/}$compared with wild-type mice and undetectable in other Cyp3a-/- tissues. CYP3A4 expression in the liver $\left(\mathrm{Cyp}^{3} \mathrm{a}^{-/-} \mathrm{A}\right)$ or intestine $\left(\mathrm{Cyp}^{3} \mathrm{a}^{-/-V}\right)$ decreased accumulation of docetaxel in these organs by 19 -fold and nearly 4-fold, respectively, compared with Cyp3a-/- mice. Accordingly, docetaxel metabolites were increased in liver and intestine of Cyp3a--A and Сур3 $3 \mathrm{a}^{-/-V}$ mice, respectively. Expression of CYP3A4 in the liver of Сур $3 \mathrm{a}^{-/-} \mathrm{A}$ mice markedly decreased tissue accumulation of docetaxel not only in liver, but also in intestine (5.8-fold), compared with Cyp3 $3 \mathrm{a}^{-/-}$mice. This might reflect decreased hepatobiliary excretion of parent docetaxel in this strain. Similarly, as the Сур $3 \mathrm{a}^{-/-}$A mice do not have CYP3A4 activity in small intestine, the increased metabolites measured in the small intestine are most likely formed in the liver and released into the intestine via bile.

To determine the effect of Cyp3a on the excretion of docetaxel and metabolites into feces and urine, wild-type, Сур3 $3 \mathrm{a}^{-/-}$, Сур $3 \mathrm{a}^{-/-\mathrm{A}}$, and Сур $3 \mathrm{a}^{-/-} \mathrm{V}$ mice housed in metabolic cages received i.v. docetaxel $(10 \mathrm{mg} / \mathrm{kg})$. Fecal and urine samples were collected for 48 hours and docetaxel and metabolites M1-4 were determined by HPLC. Urinary levels of docetaxel and M1-4 in all 4 strains remained below $1.4 \%$ of the dose (data not shown). In feces of wild-type mice, $5.6 \% \pm 1.6 \%$ of the total dose could be retrieved as docetaxel and $33 \% \pm 4.2 \%$ as M1-4 metabolites, compared with $47 \% \pm 4.6 \%$ docetaxel and $1.6 \% \pm 0.4 \%$ metabolites in Cyp3a ${ }^{-/-}$mice $(P<0.001)$, illustrating the profound impact of Сyp3a on metabolic docetaxel detoxification (Figure 5B). Transgenic CYP3A4 expression in either liver or intestine yielded intermediate results (Figure 5B). Thus, whereas wild-type mice excreted predominantly docetaxel metabolites M1-4 in the feces, in the absence of Cyp3a docetaxel was mainly excreted as unchanged drug. The low amounts of M1-4 detected in the liver and feces of Cyp3a-/- mice indicate minor metabolism of docetaxel, presumably by other Cyps, for instance, members of the Cyp1, Cyp2c, Сyp2d, and Cyp2e families (19), or by intestinal bacteria.

Increased docetaxel toxicity in Cyp3a-knockout mice. Cyp3a deficiency resulted in a markedly increased sensitivity to docetaxel toxicity, as we noted in a pilot chemotherapy experiment, where wild-type $(n=5)$ and Cyp3a- ${ }^{-/}(n=6)$ mice received i.v. docetaxel $(10 \mathrm{mg} / \mathrm{kg})$ on 5 consecutive days. Initial body weight loss in Cyp3a $\mathrm{a}^{-/-}$mice was much more rapid $(11.1 \% \pm 2.4 \%)$ than in wild-type mice $(3.8 \% \pm 3.1 \% ; P<0.01)$ on day 4 , when daily i.p. glucose/water $/ \mathrm{NaCl}$ supplementation ( $1.5 \mathrm{ml}$ on days 4,5 , and 6 ) was initiated. In spite 



\section{Figure 5}

Effect of Cyp3a/CYP3A4 and Cyp3a/CYP3A4 inhibition on docetaxel metabolism and excretion. (A) The reduction of docetaxel exposure by endogenous Сур3a in wild-type mice and transgenic CYP3A4 in the intestine of Cyp3a ${ }^{-1-} \mathrm{V}$ mice was inhibited by oral administration of the CYP3A inhibitor ritonavir. Ritonavir $(50 \mathrm{mg} / \mathrm{kg})$ was administered orally to wild-type, Сур3 $\mathrm{a}^{--}$, and $\mathrm{Cyp} \mathrm{a}^{--} \mathrm{V}$ mice 30 minutes before and blood samples were obtained 1 hour after the oral administration of docetaxel $(10 \mathrm{mg} / \mathrm{kg}$ ). (B) Fecal excretion of docetaxel and metabo-

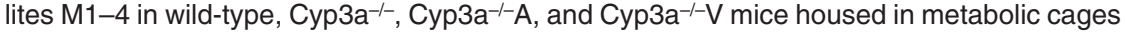
for 48 hours. Docetaxel $(10 \mathrm{mg} / \mathrm{kg})$ was administered i.v. to mice housed in metabolic cages, and docetaxel and metabolites M1-4 were measured in feces between 0 and 48 hours after administration. Values represent the mean $\pm \mathrm{SD} ; n=3-4 ;{ }^{*} P<0.05,{ }^{* \star} P<0.01,{ }^{* \star *} P<0.001$, treatment with versus without ritonavir (A) or compared with Сyp3 $\mathrm{a}^{-/-}$mice (B).

of the supplementation, all Cyp3 $3 \mathrm{a}^{-/-}$mice deteriorated quickly and had to be euthanized on days 6 and 7. In contrast, wild-type mice gradually lost weight until day 9-11 (to a maximum of $18.5 \% \pm 5.0 \%$ ) and then fully recovered, regaining normal weight around day 25 . Legal and ethical considerations precluded further analysis of this toxicity difference, but the all-or-nothing outcome illustrates the importance of Сyp3a in limiting docetaxel toxicity.

\section{Discussion}

We generated mice deficient for all 8 full-length Cyp3a genes to allow the in vivo analysis of physiological, pharmacological, and toxicological functions of the CYP3A complex. Surprisingly, despite a range of proposed physiological roles for Сур3a, Сур3adeficient mice are viable and fertile and do not show marked spontaneous abnormalities. Cyp3a-knockout mice did display a greatly impaired ability to detoxify the cytotoxic drug docetaxel. We further found that expression of transgenic human CYP3A4 in the intestine alone was sufficient to virtually block parental docetaxel entry from the gut but had very little effect on the systemic clearance of docetaxel. In contrast, liver expression of transgenic CYP3A4 greatly reduced systemic exposure after i.v. docetaxel administration but had a relatively modest impact on oral administration. These data demonstrate pronounced differences in tissue-specific contributions of CYP3A4 to first-pass drug metabolism. Our results further suggest that the Cyp3as evolved primarily to protect the organism from xenobiotic toxin exposure rather than for other physiological functions.

Next to the conventional targeting of Cyp3a13, we deleted approximately $0.8 \mathrm{Mb}$ of genomic DNA from chromosome 5, spanning all remaining full-length Cyp3a genes. Yet the Cyp3aknockout mice showed remarkably few abnormalities. Viable mice with a homozygous deletion of gene "deserts" of up to $1.5 \mathrm{Mb}$, devoid of identifiable genes, have been described before (20), but the generation of viable mice with a homozygous deletion of $0.8 \mathrm{Mb}$ of genomic DNA, harboring at least 7 full-length genes, has to our knowledge not been described. This suggests a remarkable tolerance for large genomic deletions, even of gene-rich areas. Clearly, however, the Cyp3a cluster does not constitute "disposable DNA," as was suggested for the gene deserts (20).

The relative contribution of the liver and small intestine to first-pass metabolism of drugs and other xenobiotics is the subject of extensive discussion (13-15). Whereas the specific activity of hepatic and intestinal microsomal CYP3A4 (expressed per picomole of P450) can be comparable, based upon much higher estimates of the total amount of CYP3A in liver, a generally dominant role for the liver in first-pass metabolism has been proposed. However, the CYP3A4 substrate felodipine was shown to undergo substantial metabolism in vivo in enterocytes during absorption from the lumen of the bowel (15), which suggests that the intestinal contribution to presystemic metabolism of drugs can be marked. The extensive overlap in substrate specificity between CYP3A and multidrug efflux transporters such as P-gp might further boost the intestinal first-pass elimination capacity. These transporters may reduce effective drug concentration in the enterocyte during absorption, preventing saturation of CYP3A and thus allowing efficient first-pass metabolism (15). Such aspects cannot be addressed in in vitro microsomal studies.

Thus far, a clearly defined in vivo model for studying hepatic versus intestinal contributions of CYP3A to first-pass metabolism was lacking. By generating transgenic mice constitutively expressing human CYP3A4 in liver or intestine and crossing these into a Сур $3 \mathrm{a}^{-/-}$background, we have now obtained such a model. After oral docetaxel administration, intestinal activity of CYP3A4 in Cyp3a $\mathrm{a}^{-/-V}$ mice decreased the docetaxel exposure 16.6-fold compared with that in Cyp3a-/- mice, down to wild-type levels. This demonstrates that intestinal CYP3A4 activity can function as an extremely efficient barrier to xenobiotic entry, even without the contribution of the liver. Liver activity of CYP3A4 could decrease docetaxel exposure after oral administration by only 2.2 -fold, even though the specific in vitro intrinsic clearances of CYP3A4 in this organ and in intestine were similar (Tables 1 and 2). Upon i.v. docetaxel administration, liver CYP3A4 activity decreased the plasma exposure 5.4-fold, whereas intestinal CYP3A4 activity only decreased the docetaxel plasma exposure by 1.4-fold, illustrating a very modest role for intestinal CYP3A4 in systemic elimination. Thus, whereas liver expression of CYP3A4 is the main contributor for systemic clearance of docetaxel, intestinal expression of CYP3A4 is the primary determinant for preventing docetaxel from entering the circulation from the gut lumen. In addition to being a substrate of CYP3A, docetaxel is also transported by P-gp (21). Therefore, P-gp might well contribute to the efficiency of CYP3A-mediated docetaxel metabolism in the intestine, a point worth investigating in future studies. 


\section{Table 3}

Docetaxel and metabolites M1-4 $(\mu \mathrm{g} / \mathrm{g})$ recovered from plasma and tissues 1 hour after i.v. administration of docetaxel $(10 \mathrm{mg} / \mathrm{kg})$ to wild-

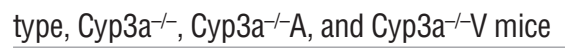

\begin{tabular}{|c|c|c|c|c|}
\hline Docetaxel & WT & Сурза ${ }^{-/-}$ & Сур3a-/-A & Сур3a-/-V \\
\hline Plasma & $0.1 \pm 0.0^{\mathrm{A}}$ & $1.5 \pm 0.1$ & $0.1 \pm 0.0^{\mathrm{A}}$ & $1.3 \pm 0.1^{\mathrm{B}}$ \\
\hline Liver & $4.3 \pm 0.5^{A}$ & $33 \pm 4.6$ & $1.7 \pm 0.2^{A}$ & $29 \pm 3.3$ \\
\hline Kidney & $6.4 \pm 0.2^{\mathrm{C}}$ & $7.8 \pm 0.5$ & $4.0 \pm 0.3^{A}$ & $6.7 \pm 0.4^{\mathrm{B}}$ \\
\hline Lung & $5.1 \pm 0.8^{8}$ & $6.5 \pm 0.3$ & $4.7 \pm 0.6^{C}$ & $6.2 \pm 0.2$ \\
\hline Spleen & $4.7 \pm 0.3$ & $5.6 \pm 0.9$ & $3.7 \pm 0.6^{\mathrm{B}}$ & $5.4 \pm 0.5$ \\
\hline Small intestine & $5.0 \pm 0.7^{A}$ & $25 \pm 3.3$ & $4.3 \pm 0.8^{A}$ & $6.6 \pm 0.7^{\mathrm{A}}$ \\
\hline Colon & $4.0 \pm 0.1^{B}$ & $5.8 \pm 1.1$ & $3.7 \pm 0.8^{8}$ & $3.0 \pm 0.3^{c}$ \\
\hline Metabolite M1-4 & WT & Сурза $\mathrm{a}^{--}$ & Сур3а $\mathrm{a}^{-1-A}$ & Сур3а $\mathrm{a}^{-1-\mathrm{V}}$ \\
\hline Plasma & $<L L Q$ & $<L L Q$ & $<L L Q$ & $<L L Q$ \\
\hline Liver & $1.98 \pm 0.5^{\mathrm{A}}$ & $0.08 \pm 0.1$ & $1.09 \pm 1.1$ & $0.03 \pm 0.1$ \\
\hline Kidney & $<L L Q$ & $<L L Q$ & $<L L Q$ & $0.40 \pm 0.1$ \\
\hline Lung & $0.04 \pm 0.1$ & $<L L Q$ & $0.18 \pm 0.0$ & $<L L Q$ \\
\hline Spleen & $<L L Q$ & $<L L Q$ & $<L L Q$ & $<L L Q$ \\
\hline Small intestine & $12.2 \pm 2.2$ & $<L L Q$ & $3.34 \pm 1.5$ & $1.65 \pm 0.2$ \\
\hline Colon & $2.11 \pm 1.3$ & $<L L Q$ & $0.80 \pm 0.6$ & $0.58 \pm 0.1$ \\
\hline
\end{tabular}

Only intestinal tissue was measured. Docetaxel and metabolites were undetectable in testis and brain of all strains (data not shown). LLQ, lower limit of quantification $(0.05 \mu \mathrm{g} / \mathrm{ml})$. Values represent mean $\pm \mathrm{SD}(n=4)$. ${ }^{A} P<0.001$, ${ }^{\mathrm{B}} P<0.05,{ }^{\mathrm{C}} P<0.01$ compared with $C y p 3 \mathrm{a}^{-/-}$mice.

The hepatic and intestinal microsomal CYP3A4 activity in the various transgenic strains was of the same order as the activity seen in wild-type mice and pooled human samples (Table 1). This illustrates that these mice have physiologically relevant transgenic CYP3A4 activity in liver or intestine, making them appropriate "humanized" models for studying CYP3A4-mediated metabolism in vivo.

CYP3A metabolizes various steroids, such as progesterone, estradiol, testosterone, and corticosterone, and could therefore be involved in the regulation of steroid hormone levels in plasma or tissues. Because we could not find any abnormalities in viability and reproductive capacity of $\mathrm{Cyp} 3 \mathrm{a}^{-/-}$mice, essential roles for Сур3a in endogenous steroid regulation seem unlikely. However, a protective role against dietary steroids is still imaginable. Based upon its expression in kidney and its ability to metabolize cortisol to $6 \beta$-hydroxycortisol, a physiological regulator of $\mathrm{Na}^{+}$transport in renal epithelia (5), it was hypothesized that polymorphically expressed CYP3A5 may have a role in salt-sensitive hypertension by increasing renal retention of $\mathrm{Na}^{+}(22)$. Although some clinical studies showed association between CYP3A5 polymorphisms and blood pressure control $(3,4)$, other studies did not (23). In our Cyp3a-deficient mice, we did not see any blood pressure-related pathology, such as cardiac hypertrophy or vascular lesions, nor could we detect differences in blood pressure parameters compared with wild-type controls. This makes an important role for Сyp3a in blood pressure regulation less likely.

Because of its low oral bioavailability, docetaxel is routinely administered i.v. in humans. However, oral drug treatment is generally less costly and more patient-friendly, and repeated dosing for chronic treatment regimens is easier. We show here that the absence of Cyp3a activity alone increased the systemic exposure of docetaxel 18-fold after oral administration and that oral administration of the CYP3A inhibitor ritonavir could improve the docetaxel plasma concentration by 10 -fold and 21 -fold in wild-type and Cyp3a- $\mathrm{a}^{-/} \mathrm{V}$ mice, respectively. This suggests that inhibition of CYP3A activity could substantially improve the oral availability of docetaxel in humans. Our ritonavir inhibition data (Figure 5A) indicate that ritonavir could have relatively high efficacy and specificity for this application, as was previously suggested based on ritonavir inhibition data in Cyp3a-proficient mice (21).

In spite of the current use of the i.v. administration route, there is still a large interpatient variability in docetaxel exposure (AUC) and clearance, which may profoundly affect both efficacy and toxicity of the chemotherapy (9). We found a 6.8-fold reduced clearance of docetaxel in Cyp3a-deficient mice upon i.v. administration, and this resulted in markedly increased toxicity. This suggests that interindividual variation in CYP3A activity could well underlie the variation in docetaxel clearance and toxicity observed in the clinic. In fact, as a $50 \%$ decrease in docetaxel clearance in patients increased the odds of developing grade 4 neutropenia and febrile neutropenia by 4.3-fold and 3.0-fold, respectively, it is very likely that variation in CYP3A activity is a main factor in inefficacy or toxicity risks of docetaxel $(11,12)$.

Because CYP3A is highly variably expressed, can be extensively induced or inhibited by a range of drugs and dietary compounds, and affects so many drugs (24), it is essential to investigate early on what the in vivo consequences are of CYP3A metabolism of newly developed drugs. This should allow assessment of toxicity, efficacy, and drug-drug and drugfood interaction risks. We expect that the Cyp3a-knockout mice and the mice with transgenic human CYP3A4 expression in liver or intestine, in the Cyp3a-knockout background, will provide excellent tools to study the impact of CYP3A on these parameters. Furthermore, combination of these strains with knockout and transgenic mice modified for other pharmacologically important proteins (e.g., active efflux transporters) will yield powerful tools for elucidating the in vivo interactions of CYP3A with other detoxification systems (25).

\section{Methods}

Animals. Mice were housed and handled according to institutional guidelines. All mouse experiments was approved by the Animal Experiments Review Board of the Netherlands Cancer Institute, complying with Dutch legislation. Animals used in this study were wild-type, Сyp3a-knockout (Сур3 $\mathrm{a}^{-/-}$), or humanized Сyp3 $\mathrm{a}^{-/-}$mice with specific expression of transgenic CYP3A4 in liver (Cyp3a--A) or intestine (Cyp3a--V), all of a comparable genetic background (FVB). Animals were kept in a temperature-controlled environment with a 12-hour light/12-hour dark cycle. They received a standard diet (AM-II; Hope Farms) and acidified water ad libitum.

Cloning of 129/Ola Cyp3a13, Cyp3a57, and Cyp3a59 genomic DNA and construction of targeting vectors for the generation of Cyp3 $a^{-/-}$mice. The mouse Cyp3a genes were mapped according to their relative order in the genome by restriction site analysis of PAC and phage lambda clones, isolated from mouse genomic libraries by hybridization with Cyp3a11, Cyp3a16, Cyp3a25, and Cyp3a13 cDNAs, and using data from the Celera (www. celera.com) and ENSEMBL (www.ensembl.org) databases. Phage lambda clones from a murine genomic library derived from the 129/Ola ES cells, containing Cyp3a13, Cyp3a57, and Cyp3a59 sequences, provided material for the construction of suitable gene targeting vectors. A targeting vector for disruption of Cyp3a13 was made wherein a 4.3-kb BglII fragment including exons 1 and 2 and the putative promoter region of Cyp3a13 was 
replaced with a 1.8-kb Pgk-hygromycin cassette in reverse-transcriptional orientation. A 10.0-kb SacI linearized DNA fragment was used for electroporation into ES cells. For both the centromeric and telomeric side of the Сур3a cluster, targeting vectors were constructed allowing insertion of loxP sequences at the cluster flanks. For the centromeric side of the Сур3a cluster, a targeting vector was made in which a 35-bp BstEII fragment in the region between exons 2 and 3 of Cyp $3 a 57$ was replaced by a 2 -kb $P g k$-neomycin cassette with loxP sequences in reverse-transcriptional orientation. A 13-kb BamHI linearized DNA fragment was used for electroporation into ES cells. For the telomeric side of the cluster, a targeting vector was made in which $2.2 \mathrm{~kb}$ downstream of exon 13 of Cyp3a59, a $P g k$-thymidine kinase cassette in reverse-transcriptional orientation was inserted into a BbrpI restriction site and a Pgk-hygromycin cassette with loxP sequences in reverse-transcriptional orientation $(2.3 \mathrm{~kb})$ was inserted into a NheI restriction site. A 14.0-kb MfeI linearized DNA fragment was used for electroporation into targeted ES cells.

Electroporation and selection for Cyp3a-recombinant ES cells. 129/Ola-derived E14 ES cells were cultured as described previously (26). Electroporation with linearized DNA of Cyp3a13, Cyp3a57, and Cyp3a59 targeting vectors, or with circular DNA encoding Cre recombinase/puromycin selection genes, and subsequent selection were performed as described previously (26).

PCR and Southern blot analysis of Cyp3a-recombinant ES cells and generation of Cyp3 $3 a^{-/-}$mice. Correct homologous recombination of the Cyp3a13 targeting construct was confirmed by Southern blot analysis. Hybridization of EcoRV-digested genomic DNA with the 3' Cyp3a13 probe yielded a wild-type band of $16.2 \mathrm{~kb}$ and a targeted band of $8.6 \mathrm{~kb}$. Hybridization of EcoRV-digested genomic DNA with the 5' Cyp3a13 probe resulted in a wild-type band of $16.2 \mathrm{~kb}$ and a targeted band of $3.4 \mathrm{~kb}$. Absence of additional Cyp3a13 targeting construct integrations into the genome was confirmed with a hygromycin-specific probe.

Correct homologous recombination of the Cyp3a57 targeting construct was confirmed by Southern blot analysis. Hybridization of NcoI-digested genomic DNA with the $3^{\prime}$ Cyp3a57 probe resulted in a wild-type band of $12.5 \mathrm{~kb}$ and a targeted band of $10.8 \mathrm{~kb}$. Hybridization of ScaI-digested genomic DNA with the 5' Cyp3a57 probe resulted in a wild-type band of $10.3 \mathrm{~kb}$ and a targeted band of $7.0 \mathrm{~kb}$. Absence of additional Cyp3a57 construct integrations into the genome was confirmed with a neomycinspecific probe. An ES cell clone with correctly inserted loxP-neomycin into Cyp3a57 and correct karyotype was electroporated with the loxP-hygromycin Cyp3a59 targeting construct.

Correct homologous recombination of the Cyp3a59 targeting construct was confirmed by Southern blot analysis. Hybridization of Asp718-digested genomic DNA with the 3' Cyp3a59 probe resulted in a wild-type band of $13.5 \mathrm{~kb}$ and a targeted band of $12.7 \mathrm{~kb}$. Hybridization of Asp718-digested genomic DNA with the 5' Cyp3a59 probe resulted in a wild-type band of $13.5 \mathrm{~kb}$ and a targeted band of $5.9 \mathrm{~kb}$. Due to high homology among the Cyp3a genes, 2 additional bands were recognized by the 5' Cyp 3 a59 probe: a $14.4-\mathrm{kb}$ band and a $4.0-\mathrm{kb}$ band from Cyp $3 \mathrm{a} 25$ and Cyp3a57, respectively.

Clones with correctly integrated loxP sites at both flanks of the cluster were cotransfected with Pgk-Cre recombinase and Pgk-puromycin expression plasmids in order to excise the cluster. After selection with puromycin, surviving ES cell clones were treated with ganciclovir. Due to the localization of the Pgk-thymidine kinase cassette in between the loxP sequences inserted at both flanks, only clones that had their Сур3a cluster deleted survived the ganciclovir treatment. Correct excision of the Cyp3a cluster by Cre recombinase was confirmed by PCR (primers for cluster deletion at the Cyp3a57 flank: 5'-GGTAGCTAGTATAGCAGAACC-3'; and at the Cyp3a59 flank: 5'-GTACATACAGCTCAGAGCCTG-3') and Southern blot analysis. Hybridization of ScaI-digested genomic DNA with the 5' Cyp3a57 probe resulted in a wild-type band of $10.3 \mathrm{~kb}$ and, instead of the Cyp3a57-targeted band of $7.0 \mathrm{~kb}$, a 9.4-kb band indicative of the cluster deletion. Absence of additional Cyp3a59-construct integrations into the genome was confirmed with a thymidine kinase-specific PCR.

Chimeric mice were generated by microinjection of 2 independently targeted ES clones (with correct karyotype) into blastocysts. Using this approach, 2 independent Cyp3a13 $13^{-/}$mouse lines and 2 independent Сур3a cluster $/-$ mouse lines were established. Сyp3a13-/- mice and Сур3a cluster $^{-/}$mice are viable and fertile. Hematological, plasma clinical chemistry, and pathological examination of male and female Cyp3a13-/- mice and Сyp3a cluster ${ }^{-/}$mice at approximately 12 weeks of age did not reveal any abnormalities (data not shown). Cyp3a cluster ${ }^{-1}$ mice were backcrossed with Сур3a13 $3^{-/}$mice and screened for allelic crossover of the targeted Cyp3a13 and deleted cluster. The resulting combination of Сyp3a13 $1 /-$ and Сyp3a cluster $/-$ yielded a total family Cyp3a-/- mouse strain, which was backcrossed to a homogeneous (>99\%) FVB background.

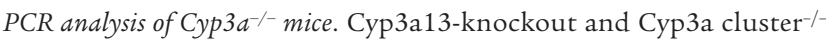
founder lines were detected by PCR screen. DNA was extracted from ear snips or tail tips of mice. For the detection of the wild-type Cyp3a13 allele, forward 5'-CCTGTTTGGCACAGATGCTCAGC-3' (located approximately 173 bp downstream of exon 2 of the Cyp3a13 gene) and reverse $5^{\prime}$ GGAGATGTCACCTCTACACACAGC-3' (located approximately $541 \mathrm{bp}$ downstream of exon 2 of the Cyp3a13 gene) primers, yielding a 391-bp band, were used. Forward 5'-GGAGCAAAGCTGCTATTGGC-3' (located within the Pgk-hygromycin cassette) and reverse 5'-GGAGATGTCACCTCTACACACAGC-3' (located approximately 541 bp downstream of exon 2 of the Cyp3a13 gene) primers were used for the detection of the modified Cyp3a13 allele, yielding a 570-bp band. Forward 5'-GGTAGCTAGTATAGCAGAACC-3' (located approximately $1.5 \mathrm{~kb}$ downstream of exon 2 of the Cyp3a57 gene) and reverse 5'-GTACATACAGCTCAGAGCCTG-3' (located approximately $2.4 \mathrm{~kb}$ downstream of exon 13 of the Cyp3a59 gene) primers were used for the detection of the Cyp3a-deleted cluster allele, which yields a 363-bp band. For the detection of the wild-type cluster allele, forward 5'-CCACCAAATTGACATGAGTCC-3' (located approximately $1.8 \mathrm{~kb}$ downstream of exon 13 of the Cyp3a59 gene) and reverse 5'-GTACATACAGCTCAGAGCCTG-3' (located approximately $2.4 \mathrm{~kb}$ downstream of exon 13 of the Cyp3a59 gene) primers were used, yielding a 617-bp band.

Southern and Northern blot analysis of Cyp3 $3 a^{-/-}$mice. Cyp3a11 and Cyp3a25 cDNA probes were used for the detection of Cyp3a11-like genes (cDNA sequence identity 93\%, 95\%, and 95\% with Cyp3a16, Cyp3a41, and Cyp3a44, respectively) and Cyp3a25-like genes (cDNA sequence identity $93 \%$ and 97\% with Cyp3a57 and Cyp3a59, respectively) in Asp718-digested kidney DNA. Cyp3a13 cDNA was used as a probe in Northern blot analysis of RNA isolated from several organs. Equal loading across the lanes was confirmed by GAPDH hybridization.

Oligoarray analysis of $\mathrm{Cyp} 3 \mathrm{a}^{-/-}$mice. $32 \mathrm{~K}$ murine oligo microarrays were hybridized with Cy dye-labeled pooled liver and intestinal amplified RNA $(n=5)$ of adult wild-type and Cyp3 $\mathrm{a}^{-/-}$males, using the TECAN HS 4800 hybridization station. The original data and detailed protocols for RNA isolation, amplification, labeling, hybridization, and gene ID list are available at http://microarrays.nki.nl and are deposited at ArrayExpress, EBI (http://www.ebi.ac.uk/arrayexpress), accession number A-NCMF-1.

Western blot analysis. Crude membrane fractions were prepared from mouse liver, kidney, and small intestine as described previously (18). Blots were probed with rabbit anti-human CYP3A4 polyclonal antibody (RDICYP3A4abr [1:1,000]; RDI), followed by HRP-labeled antibody (Santa Cruz Biotechnology Inc. or Amersham). All blots had equal amounts of CYP3A4 standard loaded (0.05 pmol; BD). Equal loading across the lanes (or intended 10-fold differences) was confirmed with total protein staining (ponceau $\mathrm{S}$ and India ink). 
Clinical-chemical and hematological analysis of plasma and blood. Standard clinical chemistry analyses on plasma were performed on a Roche Hitachi 917 analyzer to determine levels of bilirubin, alkaline phosphatase, aspartate aminotransaminase, alanine aminotransaminase, $\gamma$-glutamyl transferase, lactate dehydrogenase, creatinine, ureum, $\mathrm{Na}^{+}, \mathrm{K}^{+}, \mathrm{Ca}^{2+}$, phosphate, total protein, albumin, and cholesterol. Hemoglobin, hematocrit, mean corpuscular volume, red and white blood cells, and platelets were analyzed in peripheral blood on a Cell Dyn 1200 analyzer (Abbott). Plasma estradiol and testosterone were measured from wild-type and Сyp3a-/- diestrus females (assessed by May-Grünwald-Giemsa staining of vaginal smears) and males, respectively, by quantitative immunoassays (Roche).

Histological analysis. Tissues were fixed in $4 \%$ phosphate-buffered formalin, embedded in paraffin, sectioned at $4 \mu \mathrm{m}$, and stained with $\mathrm{H} \& \mathrm{E}$ according to standard procedures. Immunohistochemistry on wild-type and Сур3 $\mathrm{a}^{-/-}$ tissues was conducted with a rabbit anti-rat Cyp3a1 polyclonal antibody (CR3310; Biomol International) and secondary antibody conjugated to HRP-labeled polymers (EnVision+ System-HRP; DakoCytomation).

Blood pressure measurements. Noninvasive blood pressure measurements (noninvasive BP monitor V2.10; Columbus Instruments) were conducted in female wild-type and Cyp3 $\mathrm{a}^{-/}$mice of approximate 6 weeks of age $(n=6)$. Heart rate, DBP, SBP, and MBP were determined by tail cuff measurements, 30 minutes after placement in a standard mouse constrainer.

Microsomal experiment. Mouse liver and intestinal microsomes were prepared as described previously (27). Kinetic parameters were determined by incubating docetaxel over a concentration range $(0-40 \mu \mathrm{M})$ in a mixture $(200 \mu \mathrm{l})$ containing $0.5 \mathrm{mg}$ protein/ $\mathrm{ml}$ liver microsomes or $1 \mathrm{mg}$ protein $/ \mathrm{ml}$ intestinal microsomes, $\mathrm{pH}$ 7.4. Pooled human liver and intestinal microsomes were from BD. After preincubation for 5 minutes at $37^{\circ} \mathrm{C}$, reactions were started by adding NADPH Regenerating System (BD). Incubation (within linear range of product formation) proceeded for 15 minutes (liver) or 20 minutes (intestine) and was terminated by adding $100 \mu \mathrm{l}$ of ice-cold acetonitrile. Control experiments, either omitting cofactor or docetaxel, or including the CYP3A inhibitor ketoconazole $(2.5 \mu \mathrm{M})$, were performed to ascertain CYP-dependent metabolism. Levels of docetaxel and metabolites in supernatant (10 minutes, 6,800 g) were determined by reversed-phase HPLC as described previously (21), with minor modifications. The mobile phase consisted of $45 \%$ acetonitrile/10\% methanol/45\% $10 \mathrm{mM} \mathrm{NH}_{4}$-acetate buffer ( $\mathrm{pH}$ 5) and a Symmetry C18 column; $2.1 \times 150 \mathrm{~mm}, 3.5 \mu \mathrm{m}$ (Waters) was used. $K_{\mathrm{m}}$ and $V_{\max }$ values were analyzed using the standard Michaelis-Menten equation: $V=V_{\max } \times[S] / K_{\mathrm{m}}+[S]$, using GraphPad Prism 4.0. The intrinsic clearance was calculated as the $V_{\max } / K_{\mathrm{m}}$ ratio.

Docetaxel pharmacokinetics. Docetaxel $(10 \mathrm{mg} / \mathrm{ml})$ formulated in polysorbate $80 /$ ethanol/water (20:13:67, vol/vol/vol) (Taxotere; Aventis) was diluted with saline $(0.9 \% \mathrm{NaCl})$ and administered by oral gavage or by injection into the tail vein of mice lightly anesthetized with methoxyflurane (Metofane; Medical Developments Australia Pty.). At indicated time points after docetaxel administration, blood samples were taken by cardiac puncture under methoxyflurane anesthesia, after which mice were sacrificed by cervical dislocation. Organs were removed, and intestinal contents were separated from intestinal tissue. Tissue samples were homogenized (Polytron blender) in a $4 \%$ (wt/vol) BSA solution. In the inhibition experiment, ritonavir $(50 \mathrm{mg} / \mathrm{kg})$ was administered orally 30 minutes before and blood samples were obtained 1 hour after the oral administration of docetaxel. A mass balance study was performed with Ruco Type M/1 metabolic cages. Mice were allowed to accustom to the cages for 2 days before receiving docetaxel $(10 \mathrm{mg} / \mathrm{kg}$ ) injected into the tail vein under light methoxyflurane anesthesia. Feces and urine were collected in $0-4,4-8,8-24$, and $24-48$ hour fractions after drug administration. Urine was diluted in blank human plasma and feces homogenized in a $4 \%(\mathrm{wt} / \mathrm{vol}) \mathrm{BSA}$ solution. Levels of docetaxel and metabolites (M-1, M-2, M-3, and M-4, i.e., RPR111026, RPR104952, RPR111059, RPR104943) in plasma, tissue, feces, and urine were determined by reversed-phase HPLC as described previously (21). If plasma samples fell below the limit of quantification $(50 \mathrm{ng} / \mathrm{ml})$, they were subsequently remeasured by HPLC-MS/MS as described previously (28).

Pharmacokinetic calculations and statistics. Mean concentrations ( $\mathrm{ng} / \mathrm{ml}$ ) for each time point were used to calculate the area under the plasma concentration versus time curve (AUC) from time 0 to the last sampling point by the linear trapezoidal rule. The elimination constant $(k)$, terminal half-life $\left(t_{1 / 2}\right)$, and plasma clearance $(\mathrm{Cl})$ were calculated as described previously, and SEs were calculated by the law of propagation of errors (18). $F$ and $S E_{\mathrm{F}}$ were calculated by the following formulas: $F=\left(\mathrm{AUC}_{\mathrm{o}} / \mathrm{AUC}_{\mathrm{iv}}\right) \times 100 \%$ and $S E_{\mathrm{F}}=F \times \sqrt{ }\left(\left[\mathrm{SE}_{\mathrm{AUCo}} / \mathrm{AUC}_{\mathrm{o}}\right]^{2}+\left[\mathrm{SE}_{\mathrm{AUCiv}} / \mathrm{AUC}_{\mathrm{iv}}\right]^{2}\right)$. Two-tailed unpaired Student's $t$ test was used to assess the significance of differences between 2 sets of data. Differences were considered to be statistically significant when $P$ was less than 0.05 .

\section{Acknowledgments}

We thank Rahmen Bin Ali and Paul Krimpenfort for blastocyst and oocyte injections; Rob Lodewijks for analysis of blood and plasma samples; Bas Thijssen for plasma docetaxel measurements by LC-MS/MS; and Ron Kerkhoven and Elly Mesman for performing the oligoarray analysis and immunohistochemistry, respectively, on mouse tissues. This work was supported in part by grants from the Dutch Cancer Society and the Technical Sciences Foundation of the Netherlands Organisation for Scientific Research (NWO/STW).

Received for publication July 30, 2007, and accepted in revised form August 15, 2007.

Address correspondence to: Alfred H. Schinkel, Division of Experimental Therapy, The Netherlands Cancer Institute, Plesmanlaan 121, 1066 CX Amsterdam, The Netherlands. Phone: 31-20-5122046; Fax: 31-20-5122050; E-mail: a.schinkel@nki.nl.
1. Guengerich, F.P. 1999. Cytochrome P-450 3A4: regulation and role in drug metabolism. Annu. Rev. Pharmacol. Toxicol. 39:1-17.

2. Kitada, M., Kamataki, T., Itahashi, K., Rikihisa, T., and Kanakubo, Y. 1987. P-450 HFLa, a form of Cytochrome P-450 purified from human fetal livers, is the $16 \alpha$-hydroxylase of dehydroepiandrosterone 3-sulfate. J. Biol. Chem. 262:13534-13537.

3. Givens, R.C., et al. 2003. CYP3A5 genotype predicts renal CYP3A activity and blood pressure in healthy adults. J. Appl. Physiol. 95:1297-1300.

4. Ho, H., et al. 2005. Association between the CYP3A5 genotype and blood pressure. Hypertension. 45:294-298.
5. Grogan, W.M., Phillips, V.M., Schuetz, E.G., Guzelian, P.S., and Watlington, C.O. 1990. Corticosterone 6 beta-hydroxylase in A6 epithelia: a steroid-inducible cytochrome P-450. Am. J. Physiol. 258:C480-C488.

6. Koch, I., et al. 2002. Interindividual variability and tissue-specificity in the expression of cytochrome P450 3A mRNA. Drug Metab. Dispos. 30:1108-1114.

7. Lamba, J.K., Lin, Y.S., Schuetz, E.G., and Thummel, K.E. 2002. Genetic contribution to variable human CYP3A-mediated metabolism. Adv. Drug Deliv. Rev. 54:1271-1294.

8. Dresser, G.K., Spence, J.D., and Bailey, D.G. 2000.
Pharmacokinetic-pharmacodynamic consequences and clinical relevance of cytochrome P450 3A4 inhibition. Clin. Pharmacokinet. 38:41-57.

9. Engels, F.K., Sparreboom, A., Mathot, R.A.A., and Verweij, J. 2005. Potential for improvement of docetaxel-based chemotherapy: a pharmacological review. Br. J. Cancer 93:173-177.

10. Marre, F., et al. 1996. Hepatic biotransformation of docetaxel (Taxotere) in vitro: involvement of the CYP3A subfamily in humans. Cancer Res. 56:1296-1302.

11. Hirth, J., et al. 2000. The effect of an individual's cytochrome CYP3A4 activity on docetaxel clearance. Clin. Cancer Res. 6:1255-1258. 
12. Bruno, R., et al. 1998. Population pharmacokinetics / pharmacodynamics of docetaxel in phase II studies in patients with cancer. J. Clin. Oncol. 16:187-196.

13. Lin, J.H., Chiba, M., and Baillie, T.A. 1999. Is the role of the small intestine in first-pass metabolism overemphasized? Pharmacol. Rev. 51:135-156.

14. Galetin, A., and Houston, J.B. 2006. Intestinal and hepatic metabolic activity of five cytochrome P450 enzymes: impact on prediction of first-pass metabolism. J. Pharmacol. Exp. Ther. 318:1220-1229.

15. Hall, S.D., et al. 1999. Molecular and physical mechanisms of first-pass extraction. Drug Metab. Dispos. 27:161-166.

16. Nelson, D.R., et al. 2004. Comparison of cytochrome P450 (CYP) genes from the mouse and human genomes, including nomenclature recommendations for genes, pseudogenes and alternative-splice variants. Pharmacogenetics. 14:1-18.

17. Oinonen, T., and Lindros, K.O. 1995. Hormonal regulation of the zonated expression of cytochrome P-450 3A in rat liver. Biochem. J. 309:55-61.

18. Van Herwaarden, A.E., et al. 2005. Midazolam and cyclosporin A metabolism in transgenic mice with liver-specific expression of human CYP3A4. Drug Metab. Dispos. 33:892-895.

19. Shou, M., et al. 1998. Role of human cytochrome P450 3A4 and 3A5 in the metabolism of taxotere and its derivatives: enzyme specificity, interindividual distribution and metabolic contribution in human liver. Pharmacogenetics. 8:391-401.

20. Nobrega, M.A., Zhu, Y., Plajzer-Frick, I., Afzal, V., and Rubin, E.M. 2004. Megabase deletions of gene deserts result in viable mice. Nature. 431:988-993.

21. Bardelmeijer, H.A., et al. 2002. Low systemic exposure of oral docetaxel in mice resulting from extensive first-pass metabolism is boosted by ritonavir. Cancer Res. 62:6158-6164.

22. Kuehl, P., et al. 2001. Sequence diversity in CYP3A promoters and characterization of the genetic basis of polymorphic CYP3A5 expression. Nat. Genet. 27:383-391.

23. Lieb, W., et al. 2006. No association of the CYP3A $5 * 1$ allele with blood pressure and left ventricular mass and geometry: the KORA/MONICA Augsburg echocardiographic substudy. Clin. Sci.
111:365-372.

24. Wilkinson, G.R. 2005. Drug metabolism and variability among patients in drug response. New Engl. J. Med. 352: 2211-2221.

25. Wacher, V.J., Wu, C.-Y., and Benet, L.Z. 1995. Overlapping substrate specificities and tissue distribution of cytochrome P450 3A and P-glycoprotein: implications for drug delivery and activity in cancer chemotherapy. Mol. Carcinog. 13:129-134.

26. Jonker, J.W., et al. 2001. Reduced hepatic uptake and intestinal excretion of organic cations in mice with a targeted disruption of the organic cation transporter 1 (Oct1 [Slc22A1]). gene. Mol. Cell. Biol. 21:5471-5477.

27. Emoto, C., et al. 2000. Characterization of cytochrome P450 enzymes involved in drug oxidations in mouse intestinal microsomes. Xenobiotica. 30:943-953.

28. Kuppens, I.E., van Maanen, M.J., Rosing, H., Schellens, J.H.M., and Beijnen, J.H. 2005. Quantitative analysis of docetaxel in human plasma using liquid chromatography coupled with tandem mass spectrometry. Biomed. Chromatogr. 19:355-361. 